\title{
PSICOLOGIA HUMANISTA DE ABRAHAM MASLOW: RECEPÇÃO E CIRCULAÇÃO NO BRASIL
}

\author{
Abraham Maslow's Humanistic Psychology: Reception and Circulation in Brazil \\ Psicología Humanista de Abraham Maslow: Recepción y Circulación en Brasil
}

Paulo Coelho Castelo Branco

Luísa Xavier De BRITo Silva

\begin{abstract}
Resumo: Esta pesquisa objetiva refletir aspectos relacionados à biografia de Abraham Maslow, seu projeto de Psicologia Humanista e o estado corrente de suas ideias no Brasil. Introduzimos, inicialmente, um esboço biográfico de Maslow. Depois, situamos a participação dele no desenvolvimento da Psicologia Humanista nos EUA. Posteriormente, apresentamos três investigações bibliográficas que analisam a recepção e a circulação das ideias de Maslow no Brasil: a primeira faz uma revisão narrativa em duas bases de dados; a segunda examina os livros de e sobre Maslow publicados no Brasil; a terceira minuta as ideias de Maslow em livros gerais de Psicologia e Administração. Evidenciamos que a vida e a obra de Maslow possibilitam uma articulação com a Psicologia Humanista, para a qual ele tinha propósitos definidos antes, durante e depois de sua ascensão. A Psicologia de Maslow é recebida parcialmente no Brasil e a circulação de suas ideias ocorre, hegemonicamente, em textos relacionados aos campos da Administração e da Psicologia Organizacional. Finalmente, apontamos outras possibilidades de pesquisas para desenvolver o legado de Maslow no cenário brasileiro.
\end{abstract}

Palavras-chaves: Abraham Maslow; Autorrealização; História da psicologia; Motivo de realização; Psicologia humanista.

\begin{abstract}
This research aims to reflect aspects about Abraham Maslow's biography, his project of Humanistic Psychology and the current status of his ideas in Brazil. We introduced, initially, a biographical sketch of Maslow. Then, we situated his participation at the development of the Humanistic Psychology in EUA. Posteriorly, we presented three bibliographical investigations analyzing the reception and the circulation of Maslow's ideas in Brazil. The first is a narrative review in two databases; the second examines the Maslow's books and books mentioning Maslow published in Brazil; the third shows the Maslow's ideas in general books of Psychology and Management. We evidenced that the life and Maslow's work allows an articulation with a Humanistic Psychology, that for it he had defined purposes before, during and after of his ascension. The Maslow's Psychology is partly received in Brazil the circulation of his ideas occurs, hegemonically, in texts related of Management area and of the Organizational Psychology. Finally, we point out other possibilities to develop the Maslow's legacy in Brazil.
\end{abstract}

Keywords: Abraham Maslow; Self actualization; History of psychology; Achievement motivation; Humanistic psychology.

Resumen: Esta pesquisa pretende reflejar aspectos relacionados con la biografía de Abraham Maslow, su proyecto de Psicología Humanista y el estado actual de sus ideas en Brasil. Introdujo inicialmente una semblanza de Maslow. Luego ponemos su participación en el desarrollo de la Psicología Humanista en el EE.UU. Adelante, se presentan tres investigaciones análisis bibliográficas de la recepción y el movimiento de las ideas de Maslow en Brasil: la primera es una revisión narrativa en dos bases de datos; la segunda examina los libros sobre Maslow publicado en Brasil; el tercer, las ideas de Maslow en los libros generales de Psicología y Gestión. Hemos demostrado que la vida y la obra de Maslow permiten una articulación con la Psicología Humanística, por el que había definido los propósitos antes, durante y después de su ascensión. La psicología de Maslow se recibe en parte en Brasil y la circulación de ideas se produce hegemónicamente en los textos relacionados con el ámbito de la Administración y en la Psicología de las Organizaciones. En final, señalamos otras posibilidades de investigación para desarrollar el legado de Maslow en la escena brasileña.

Palabras-clave: Abraham Maslow; Auto-realización; Historia de la psicología; Motivo de realización; Psicología humanista.

\section{Introdução}

São diversas as produções brasileiras que versaram a Psicologia Humanista (Justo, 1978; Boainain, 1998; Amatuzzi, 2001; Castanõn, 2007; Feijoo \& Mattar, 2009; Gomes, 2010; Ponte \& Sousa, 2011; Buys, 2011; Krüger, 2014; Holanda, 2014) e a sua História no Brasil (Gomes, Holanda \& Gauer, 2004a, 2004b). Conquanto elas apresentem introduções, reflexões, críticas e apontamentos teóricos, históricos e epistêmicos sobre o movimento humanista na Psicologia, chama a atenção um psicólogo bastante citado, porém, pouco estudado de modo exaustivo em relação aos outros expoentes humanistas, Abraham Harold Maslow. Dele, certamente vieram muitas contribuições, mas se ouve pouco sobre elas - o que o torna reconhecido, porém, pouco conhecido no cenário humanista brasileiro, popularmente mais disseminado pelas contribuições da Abordagem Centrada na Pessoa e da Gestalt-Terapia. 
O que contribuiu para tal esquecimento ou falta de conhecimento sobre Maslow no movimento humanista brasileiro? Na tentativa de responder a esse questionamento, objetivamos refletir a respeito da Psicologia Humanista de Maslow, sua recepção e circulação no Brasil. Trata-se, pois, de um estudo de cunho histórico e reflexivo sobre aspectos concernentes a biografia e obra de Maslow, seu projeto de Psicologia Humanista e o status corrente de suas ideias no Brasil.

Destarte, procedemos da seguinte lógica expositiva. Inicialmente, apresentamos um breve esboço biográfico de Maslow. Posteriormente, refletimos a relação dele com a Psicologia Humanista. Finalmente, introduzimos as noções históricas de recepção e circulação de psicologias, descrevendo três investigações bibliográficas que analisam a recepção e a circulação das ideias de Maslow no Brasil.

\section{Esboço biográfico de Abraham Maslow}

Norteados pela ideia da confecção de uma narrativa biográfica sobre um expoente, como recurso útil ao entendimento dos fatores pessoais imbricados à construção de uma ciência (Cruz, 2016), intencionamos oferecer suporte ao entendimento do quanto à vida de Abraham Maslow está vinculada à sua obra e proposta de Psicologia. O humanista tinha visão e pressuposição positivas sobre a natureza humana e suas potencialidades de autorrealização em qualquer tipo de ambiente, seja ele sadio ou não, desde que o seu comportamento esteja motivado e regulado para satisfazer suas necessidades básicas (Hall et al., 1957/2000). Com uma teoria que incluía as noções de estima e amor, geradas pelas necessidades, faltas ou por valores do ser (que transcendem condicionalidades), Maslow operacionalizou um modelo humanista de Psicologia que o levou a buscar formas de compartilhá-lo e congregá-lo a outros trabalhos afins, segundo um espírito de cooperação entre psicólogos com semelhantes visões e pressuposições.

Maslow nasceu em 01 de abril de 1908, no bairro do Brooklyn, em Nova Iorque. Foi o primogênito de sete filhos de pais imigrantes russos judeus, Samuel Maslow e Rose Schilojsky. Maslow teve uma infância humilde, sem muitos amigos, devido ao fato de o seu bairro possuir poucos judeus, o que lhe possibilitou bastante tempo para ler e estudar. Seu pai, frequentemente, desmerecia-o, chamando-o de feio. Sofrendo com isso, Maslow passou a evitar contato com as pessoas, chegando a esperar as ruas e os metrôs ficarem vazios para transitar. Sua mãe costumava privá-lo de comida, trancando a geladeira e abrindo-a conforme o seu humor. Certa vez ela descobriu que o primogênito cuidava de dois gatos no porão de sua casa e os matou a pauladas. Esse cotidiano de relações familiares tensas marcou a vida de Maslow (Hall, 1968; Hoffman, 2008).
No final da adolescência, os pais de Maslow o coagiram a se tornar advogado. Cedendo à pressão, matriculou-se, aos 17 anos, na Faculdade de Direito da Universidade de Nova Iorque, em 1926. Ao perceber que não conseguiria concluir o curso e agradar aos pais, ele pediu transferência, no ano seguinte, para a Universidade de Cornell, em Ithaca, Nova Iorque, com a finalidade de fazer um curso de Introdução à Psicologia (Hall, Lindzey \& Campbell, 1957/2000). Em Cornell, Maslow estudou com Edward Titchener, entretanto, suas experiências foram de desânimo e desinteresse pela ciência psicológica. Frustrado, o jovem estudante retornou para a cidade de Nova Iorque e matriculou-se novamente no curso de Direito, cedendo, mais uma vez, aos interesses dos seus pais (Hall, 1968).

Maslow era apaixonado, há tempos, por sua prima de primeiro grau, Bertha Goodman, o que gerou muitas intrigas familiares. Contra a vontade dos pais, ele, então com 20 anos, assumiu o relacionamento e se casou com ela, em 1928. O casal teve duas filhas, Ann e Ellen (Hoffman, 2008). Casado e motivado, Maslow encontrou forças para sair de perto dos seus pais. Em 1930, decidiu outra vez estudar Psicologia e mudou-se para Madison, com o intento de se formar na Universidade de Wisconsin, onde ele obteve êxito com os títulos de bacharel, em 1930, mestre, em 1931, e doutor, em 1934. Paralelamente à Psicologia Comportamental e Experimental, Maslow nutria um interesse pela Psicanálise de Alfred Adler. O primeiro trabalho de graduação que o estudante de Psicologia escreveu em Wisconsin foi intitulado Psicanálise e Higiene Mental como Filosofia Social do Status Quo. Entretanto, ele não teve coragem de apresentá-lo (Maslow, 1971/1975).

Maslow foi aluno de doutorado de Harry Harlow, com quem fez diversas pesquisas experimentais sobre o comportamento de primatas (Hall et al., 1957/2000; Hoffman, 2008) e publicou o seu primeiro artigo, Delayed reaction tests on primates from the lemur to the Orangutan, divulgado no Journal of Comparative Psychology, em 1932. Devido ao seu esmero, o recém-doutor foi convidado a permanecer como docente da Universidade de Wisconsin, onde chegou a se matricular como estudante na Faculdade de Medicina, tendo desistido por não ter tempo livre (Hoffman, 2008).

Em 1935, Maslow se tornou resident fellow da Universidade de Columbia, onde trabalhou com Edward Thorndike e conheceu Kurt Goldstein. Thorndike aplicara um teste de inteligência em Maslow, que obteve um coeficiente alto (QI 195). Esse acontecimento o fez acreditar mais em suas potencialidades (Hall, 1968). Sob a direção de Thorndike, ele realizou uma pesquisa sobre a sexualidade feminina, publicando diversos artigos sobre o tema. Maslow, também, contatou e foi influenciado pela Antropologia de Ruth Benedict e pela Psicologia da Gestalt, de Max Wertheimer. Foi durante essa estada que o futuro expoente humanista ratificou algumas ideias sobre autorrealização, 
consideradas pouco científicas (Hoffman, 2008). Incentivado por um psicanalista amigo, Werner Wolff, Maslow publicou, em 1937, o seu primeiro trabalho considerado fora do contexto acadêmico à época, intitulado: Personality and Patterns of Culture, publicado no livro de Ross Stagner, Psychology of Personality (Maslow, 1971/1975).

Após o término de sua residência em Columbia, em 1937, Maslow regressou à Nova Iorque ao aceitar o convite para ocupar um cargo de docente no Departamento de Psicologia do Brooklyn College, onde lecionou durante quatorze anos. Neste ínterim, em 1947, ele sofreu um ataque cardíaco, que o levou a tirar uma licença de um ano. Maslow e sua família aproveitaram para passar um tempo em Pleasanton, Califórnia, onde achava que iria descansar. No entanto, ele criou uma cooperativa de psicólogos, assumindo nela um trabalho de liderança até retornar ao Brooklyn College nos anos seguintes (Hall, 1968; Hall et al., 1957/2000).

Em 1951, Maslow recebeu o convite para trabalhar como presidente do Departamento de Psicologia da Universidade de Brandeis, em Waltham, Massachusetts. Ao se mudar, resolveu submeter-se a uma psicoterapia analítica adleriana, empreendendo um trabalho pessoal para lidar com a mágoa que tinha dos pais. Maslow chegou a reconciliar-se com o seu pai, porém nunca conseguiu perdoar à mãe pelos maus tratos (Hall, 1968). Em Brandeis, ele desenvolveu estudos sobre motivação, personalidade e autorrealização, os quais chamaram a atenção de Douglas McGregor, um professor de Administração do Massachusetts Institute of Technology, que passou a divulgar as ideias maslownianas no mundo dos negócios. Os dois se tornaram amigos e passaram a empreender trabalhos conjuntos sobre gerenciamento, trabalho autorrealizável, criatividade e liderança (Stephens, 1965/2003). Devido aos investimentos de John Rockefeller III, um magnata filantropo, Maslow conseguiu uma fonte de aplicabilidade sobre os seus estudos no circuito empresarial e desenvolveu, na prática, sua teoria sobre a hierarquia das necessidades básicas. Com a interveniência de Maslow e da Fundação Rockefeller, Kurt Goldstein chegou a trabalhar em Brandeis, em 1957-1958, e exerceu profunda influência sobre o psicólogo interveniente que lhe dedicou a obra Toward a Psychology of Being (1962). Em 1966, Maslow foi eleito presidente da American Psychological Association (APA).

As sobrecargas do trabalho e da presidência da APA, somadas à saúde cardíaca debilitada, levaram Maslow a se afastar da universidade e do meio acadêmico, em 1968. Contudo, em 1969, ele aceitou o convite para ser resident fellow da Fundação Laughlin, em Menlo Park, Califórnia (Hall et al., 1957/2000), e montou um escritório em Sand Hill Road, lugar conhecido como o berço estadunidense das ideias empresariais criativas. Nesse local, o psicólogo humanista popularizou suas perspectivas sobre empresas e gestão de pessoas que foram difundidas no Vale do Silício (Stephens, 1965/2003). Em 1970, após aceitar um cargo superior de residência da Saga Administrative
Corporation, Maslow sofreu um ataque cardíaco enquanto se exercitava caminhando em Menlo Park, vindo a óbito.

Conforme esse esboço biográfico, em suma, percebemos que Maslow iniciou a sua carreira na Psicologia Experimental, com um interesse paralelo à Psicanálise adleriana, à Psicologia da Gestalt e Organísmica e à Antropologia Cultural. Na década de 1950, em específico, Maslow (1971/1975) relatou ter dificuldades para publicar as suas ideias e pesquisas sobre motivação, autorrealização e necessidades básicas em periódicos acadêmicos reconhecidos pela APA, em razão de suas ideias serem recusadas por diversos avaliadores. Possivelmente, o motivo dessa dificuldade ocorreu por Maslow não continuar nenhuma tradição de Psicologia Comportamental, da Gestalt ou da Psicanálise. Com um histórico de superação diante das adversidades, e com um ímpeto organizador e cooperativo, o expoente humanista resolveu criar um contexto favorável à publicação e à divulgação de suas ideias e de outros psicólogos que se encontravam em semelhante situação. Em seguida, aprofundamos esse ponto na carreira de Maslow.

\section{Relação de Abraham Maslow com a Psicologia Humanista}

Envolvido pela insatisfação, e com o intuito de criar uma proposta alternativa à Psicologia Comportamental e à Psicanálise, Abraham Maslow, em 1954, começou a compilar uma lista de correspondência que continha o contato de outros psicólogos, também, insatisfeitos com o contexto relacionado à Psicologia da época (Moss, 2001; Castañon, 2007). A lista, posteriormente, batizada por Maslow de Rede Eupsiquiana, tinha o objetivo de realizar a troca de trabalhos mimeografados entre os membros que a compunham e de movimentar e divulgar artigos que as revistas convencionais da American Psychological Association (APA) rejeitavam (Holanda, 2014). Nessa lista havia nomes como os de Carl Rogers, Gordon Allport, Kurt Goldstein, Rollo May, Gardner Murphy, Anthony Sutich, apenas para citar alguns. Ressaltamos que muitos deles, a exemplo de Rogers e Allport, já gozavam de prestígio e reconhecimento no cenário estadunidense. Segundo Maslow (1962/1970), a Rede Eupsiquiana, conforme a sua conveniência, incluía apenas os nomes e contatos com os quais ele estava relacionado e se interessava. Não à toa, ele é reconhecido como o principal fundador da Psicologia Humanista (Moss, 2001).

É importante destacar que a concepção da Rede Eupsiquiana advém da ideia contracultural de uma sociedade utópica chamada Eupsiquia,

(...) that would hypothetically come into existence when a thousand psychologically healthy families migrated to a desert island. Although Maslow didn't claim to know the specifics of what this would look 
like, he knew a couple of things. The society would be philosophically anarchistic, Taoistic but loving, governed by tolerance and free choice, and lacking in violence and control. It would succeed mainly because, when given the ability to choose, healthy individuals would draw on their innate ability to make the right choices. ${ }^{1}$ (Grogan, 2013, p. 110)

No final de 1957, após uma troca de correspondências entre Maslow e Sutich, ambos chegaram à conclusão que a listagem havia alcançado seus objetivos e chegava a hora de elaborar uma revista formal (Holanda, 2014). De modo específico, essa ideia foi concretizada, em 1961, na cidade de Old Saybrook, Califórnia, com a criação do Journal of Humanistic Psychology, com um conselho editorial composto por Abraham Maslow, Kurt Goldstein, Rollo May, Lewis Mumford, Clark Moustakas, Andras Angyal e Erich Fromm. Em 1963, a Psicologia Humanista foi chancelada com o surgimento da American Association for Humanistic Psychology (Castanõn, 2007). Assim, a Psicologia Humanista se constituía dentro e à margem da APA, em razão dos resultados de suas pesquisas serem separados do campo hegemônico do pós-positivismo na Psicologia. Intencionalmente, as reuniões da associação humanista aconteciam paralelamente aos encontros da APA, congregando, por vezes, mais psicólogos que ela (Gendlin, 1992). Com efeito, diante do crescimento da Psicologia Humanista, a APA instituiu, em 1971, a Division of Humanistic Psychology, tendo designado, em 1986, um departamento de arquivos de Psicologia Humanista; e, em 1989, oficializado a publicação do Journal of Humanistic Psychology.

Conforme a divisão 32 da APA, na qual está alocada a Sociedade de Psicologia Humanista (Society for Humanistic Psychology, 2016), esta

(...) seek to contribute to psychotherapy, education, theory, research, epistemological diversity, cultural diversity, organization, management, social responsibility and change. In particular, we have been at the forefront in the development of qualitative research methodologies (§ 2).

(...) Humanistic Psychology aims to be faithful to the full range of human experience. Its foundations include philosophical humanism, existentialism and phenomenology. In the science and profession of psychology, humanistic psychology seeks to develop systematic and rigorous methods of studying human beings,

\footnotetext{
1 “(...) que, hipoteticamente, passaria a existir quando milhões de famílias, psicologicamente saudáveis, migrassem pra uma ilha deserta. Embora Maslow não soubesse falar acerca das especificidades que a caracterizaria, ele sabia expressar um pouco da sua estrutura. A sociedade seria filosoficamente anarquista, taoísta, mais amorosa, governada pela tolerância e liberdade de escolha, e com falta de violência e controle. Isso aconteceria porque, quando dada à habilidade de escolha, os indivíduos saudáveis mostrariam sua habilidade inata de fazer certas escolhas” (Grogan, 2013, p. 110, tradução nossa).
}

and to heal the fragmentary character of contemporary psychology through an ever more comprehensive and integrative approach $(\S 4) .^{2}$

Destarte, Maslow (1962/1970) apontou, segundo entendemos, quatro propósitos pertinentes ao desenvolvimento da Psicologia Humanista.

No primeiro propósito, Maslow (1962/1970) atentou para a necessidade de utilizar a ciência dominante, expandindo-a aos interesses humanistas. Para ele os métodos científicos são fundamentais para validar a Psicologia Humanista. Repudiar a ciência é um erro, mas, criticar o cientificismo ortodoxo é uma forma de “(...) ampliar os métodos e a jurisdição da ciência, de modo a torná-la mais capaz de assumir as tarefas das novas psicologias pessoais e experienciais (...). Somente a ciência pode superar as diferenças caracterológicas no ser e no crer" (p. 18). Maslow (1971) argumentou que os interesses humanistas, como os problemas do amor, dos valores, da realização, da criatividade, fossem estudados por meio de critérios científicos, ainda que não ortodoxos, para não recair no senso comum do entendimento desses temas. Maslow (1966) defendeu, pois, a Psicologia Humanista como uma ciência que deveria se valer do paradigma positivista dominante ou desenvolver pesquisas com outros modelos mais holísticos e fenomenológicos.

No segundo propósito, Maslow (1962/1970, 1960/1980) discutiu a aproximação da Psicologia com as filosofias fenomenológicas e existenciais. Maslow (1962/1970), especificamente, advertiu as ressalvas e qualidades do uso dessas filosofias na Psicologia. Conforme o autor,

(...) incute grande ênfase a que se parta do conhecimento experimental, e não de conceitos ou categorias abstratas ou apriorísticas. O existencialismo se assenta na fenomenologia, isto é usa a experiência pessoal e subjetiva como fundação sobre a qual o pensamento abstrato é construído (p. 36).

Os psicólogos americanos escutaram o apelo de Allport para a formulação de uma Psicologia Idiográfica, mas não fizeram muita coisa a respeito. Temos agora um novo impulso nessa direção pelos fenomenologistas e existencialistas (...). Se o estudo da singularidade do indivíduo não se ajusta ao que sabemos de ciência, então pior para esse conceito de ciência.

A fenomenologia tem uma história no pensamento psicológico americano, mas de um modo geral creio

\footnotetext{
“(...) procura contribuir para a psicoterapia, educação, teoria, pesquisa, diversidade epistemológica, diversidade cultural, organização, gestão, responsabilidade e mudança social. (§ 2). (...) A Psicologia Humanista objetiva ser fiel a toda gama da experiência humana. Suas bases incluem o Humanismo filosófico, o Existencialismo e a Fenomenologia. Na ciência e profissão da Psicologia, a Psicologia Humanista busca desenvolver metodos rigorsos e sistemáticos para estudar os seres humanos e para curar o carater fragmentario da Psicologia contemporânea, através de uma abordagem cada vez mais compreensiva e integradora (§ 4)” (Tradução dos autores).
} 
que definhou. Os fenomenologistas europeus (...) podem reensinar-nos a melhor maneira de compreender outro ser humano (...). É claro, uma tal conclusão é rudimentar, à luz de qualquer Filosofia positivista da ciência (p. 40).

Nesse sentido, a Fenomenologia e o Existencialismo confirmam, refinam e enfatizam as tendências já presentes na Psicologia Humanista. Considerando um contexto democrático em que ficou claro que sociedade não resolve todos os problemas do indivíduo, voltar-se para a experiência, o eu e os seus valores seria imperativo ao desenvolvimento humano. Assim, tais filosofias suprem o que a Psicologia positivista não alcança. A contribuição da Fenomenologia e do Existencialismo reside no aprofundamento de um paradigma voltado para a experiência e para a compreensão do outro como ser humano. Contudo, Maslow rogou para que essas filosofias fossem apropriadas sem que a Psicologia perdesse o seu caráter experimental e empírico de fazer ciência. Possivelmente, esse propósito foi desenvolvido a partir dos contatos de Maslow com Adrian van Kaam (Muto \& Martin, 2009), o criador do método fenomenológico empírico, e Rollo May, o tradutor dos textos dos Daseinanalistas europeus. Em 1958, Maslow participou da banca de doutorado de van Kaam (com a tese The experience of really felling understood by a person: a phenomenological study of the necessary and sufficient constituents of this subjective experience as described by 365 subjects), que lhe substituiu durante um afastamento sabático na Universidade de Brandeis, naquele ano. Em 1959, Maslow participou de um simpósio sobre a Psicologia Existencial, organizado por May na convenção anual da APA, em Cincinnati, com a sua palestra transcrita e publicada em um livro (Maslow, 1960/1980).

No terceiro propósito, Maslow (1962/1970) enfatizou um programa individual e social na emergência da Psicologia Humanista, reconhecendo-a como não puramente acadêmica, mas como uma teleologia voltada para possibilitar um modo de vida que afeta a pessoa e a sociedade. Maslow (1971) acreditou que as transformações sociais mais eficientes eram advindas de pessoas realizadas, daí o seu interesse por indivíduos que propiciaram mudanças sociais significativas, como John Kennedy, Mahatma Gandhi e Madre Teresa de Calcutá.

Por fim, no quarto propósito, Maslow (1962/1970) assumiu que a Psicologia Humanista devesse transcender para um novo sentido de humanismo, ultrapassando o humano. Em sua concepção, a Psicologia Humanista, ou Terceira Força, seria transitória para uma “(...) Quarta Psicologia ainda 'mais elevada', transpessoal, transumana, centrada mais no cosmo do que nas necessidades e interesses humanos, indo além do humanismo, da identidade, da individuação ${ }^{3}$ e quejandos [semelhantes]" (p. 12).

Nessa obra, a dicção self-actualization se encontra traduzida como individuação.
Maslow (1971) elaborou diversas significações para o termo transcendência, mas uma especificamente coadunou com uma pressuposição transpessoal: transcendência não se refere ao alcance de um nível superior de uma pessoa sobre a outra, mas implica uma percepção holística da consciência, do comportamento e da relação humana, com uma finalidade de integrar a si mesmo com outras pessoas, espécies, natureza e com o cosmo.

No transcurso dessa exposição sobre a relação de Maslow com a Psicologia Humanista, percebemos que ele tinha uma ideia clara a respeito da construção de Psicologia, seja pela criação da Rede Eupsiquiana, pela organização e colaboração em favor da assunção da Psicologia Humanista ou pelo o apontamento de uma futura Psicologia Transpessoal, que posteriormente se concretizou com a criação de um grupo de interesse dentro da Psicologia Humanista (Society for Humanistic Psychology, 2016).

\section{Recepção e circulação da Psicologia Humanista de Abraham Maslow no Brasil: investigações e reflexões}

Dissertado o breve percurso introdutório sobre Abraham Maslow e sua inserção e contribuição para a Psicologia Humanista, perfizemos três investigações bibliográficas que intencionaram analisar e discutir alguns movimentos de recepção e circulação das ideias dele no Brasil. No campo da História da Psicologia (Castelo-Branco, Rota, Miranda \& Cirino, 2016), os termos recepção e circulação servem de recursos conceituais que possibilitam o entendimento de como uma perspectiva de Psicologia, no caso a Psicologia Humanista de Maslow, migrou de um país para outro. Tal visada estabelece um diálogo entre o caráter universal (global) e local (particular-contextual) de uma Psicologia (Pickren \& Rutherford, 2012) em suas dispersões pelo mundo (Brock, 2014).

A noção de recepção (Dagfal, 2004) expressa o ato de migração de uma Psicologia que acontece conforme a apropriação de suas ideias em um determinado local, situando-a em um novo contexto social e científico, e evocando um horizonte de sentidos sobre ele, que dão continuidade, ou não, as suas contendas originais. A noção de circulação (Grynzspan, 2012), em complemento ao processo de recepção, refere-se aos movimentos que promovem a organização e a ordenação da Psicologia recebida, a partir de algumas operações sociais que possibilitam o seu fluxo e acesso em um dado espaço-tempo. Neste caso, consideramos que a cultura acadêmica de publicação de artigos em periódicos, as traduções das obras de Maslow para o português brasileiro e a produção de livros nacionais sobre Maslow constituem variadas fontes bibliográficas profícuas ao entendimento da recepção e circulação de sua Psicologia Humanista no Brasil. Para isso, estabelecemos a seguir três investigações que discorrem sobre esse entendimento. 
Em um primeiro momento investigativo, analisamos o tipo de circulação da Psicologia Humanista de Maslow em periódicos acadêmicos brasileiros. Para isso, com o intuito de averiguar a existência de publicações relacionadas a Maslow, realizamos uma revisão narrativa, inspirados pelos aportes metodológicos de Rother (2007) e Costa e Zoltowski (2014), em dois bancos de dados virtuais brasileiros, de acesso aberto, a saber, o Scientific Electronic Library Online (SciELO) e o Portal de Periódicos Eletrônicos em Psicologia (PePSIC). No campo de todos os índices das duas bibliotecas virtuais buscamos e articulamos as palavras descritoras Maslow, Motivação, Necessidades, Psicologia Humanista e Psicologia Humanística. Optamos por analisar o título, o resumo e o texto completo dos artigos, para obter maiores informações sobre Maslow. Ressaltamos que a coleta ocorreu nos meses de abril e maio de 2016. Deste modo: o critério de inclusão foi o desenvolvimento de algum aporte de Maslow no âmbito teórico ou empírico; foram excluídos artigos repetidos nos dois bancos de dados; restringimos nossa busca a artigos publicados até 2015, ano possível de verificar todas as edições lançadas.

No PePSIC foram obtidos 6 artigos resultantes da busca, todos publicados em periódicos de Psicologia: 2 oriundos de filiações institucionais brasileiras (Pérez-Ramos, 1990; Araújo \& Vieira, 2005; Ferreira, Curvello \& Monteiro, 2009; Ponte \& Sousa, 2011); e 2 de procedência mexicana (García-Cortés, Mendoza \& Carmona, 2007; Hoffman \& Ortiz, 2010). Dentre os artigos, 3 apresentam discussões relacionadas à Psicologia do Trabalho, 2 expõem contendas clínicas que utilizam alguns aportes de Maslow e 1 situa Maslow na história da Psicologia Humanista.

No SciELO foram computados 14 artigos, dos quais somente um tem procedência de uma filiação institucional estrangeira (Universidade de São Petersburgo - Rússia), havendo variação nas áreas dos periódicos, dos quais foram publicados seis textos na Enfermagem, 3 na Administração, dois na Saúde Pública, um na Zootecnia e dois na Psicologia (Gouveia, 2003; Kotliarov, 2008). Desses artigos, seis abordaram o tema das necessidades básicas em pesquisas no ambiente hospitalar; dois versaram o tema da motivação no campo da publicidade e propaganda; dois apresentou os resultados de uma pesquisa sobre os aspectos motivacionais envolvidos em praticantes de inseminações artificiais em bovinos; um discutiu os aspectos motivacionais de acompanhantes de crianças em uma enfermaria pediátrica; um desenvolveu uma pesquisa sobre tipologias considerando a teoria da motivação; um propõe um modelo matemático para explicar a teoria da motivação; um analisa motivações para competitividade no trabalho em seleções para atuar nas politicas públicas; e um investiga os determinantes afetivos e cognitivos que influenciam o trabalho de profissionais que cuidam de pessoas vivendo com o HIV.

Com efeito, no que concerne a circulação das ideias Maslow em periódicos acadêmicos, observamos que essas fazem interface com diversas áreas do conhecimento.
Dos 20 artigos compilados, 7 são teóricos e 13 empíricos. Notamos uma predominância de temas relacionados à motivação e as necessidades básicas e salientamos que esses resultados devem ser entendidos como parciais, em razão dos limites do procedimento de revisão narrativa e da restrição dos descritores e bancos utilizados. A despeito disso, consideramos escassa a circulação das ideias de Maslow em artigos publicados no Brasil, sobretudo, no que concerne a divulgação de suas ideias em periódicos de Psicologia (total de 8 artigos publicados de 1990 até 2011).

Na segunda investigação $0^{4}$ sobre a recepção da Psicologia Humanista de Maslow no Brasil, concentramo-nos no exame dos livros de Maslow publicados nos EUA e traduzidos para o português brasileiro, conforme a Tabela 1, apresentada a seguir.

Tabela 1: Livros de Maslow publicados e traduzidos para o português brasileiro

\begin{tabular}{lc}
\multicolumn{1}{c}{$\begin{array}{c}\text { Livro (Ano de } \\
\text { publicação original) }\end{array}$} & $\begin{array}{c}\text { Tradução para o Português Brasileiro } \\
\text { (Ano da publicação) }\end{array}$ \\
\hline Motivation and Personality 1954) & - \\
\hline Toward a Psychology of Being (1962) & Introdução à Psicologia do Ser (1970) \\
\hline $\begin{array}{l}\text { Religions, Values, and } \\
\text { Peak Experiences (1964) }\end{array}$ & - \\
\hline Eupsychian Management (1965) & $\begin{array}{c}\text { Maslow no Gerenciamento (2000) / } \\
\text { Diário de Negócios de Maslow (2003) }\end{array}$ \\
\hline $\begin{array}{l}\text { The Psychology of Science: } \\
\text { a Reconnaissance (1966) }\end{array}$ & - \\
\hline $\begin{array}{l}\text { The Farther Reaches of Human } \\
\text { Nature (1971) }\end{array}$ & - \\
\hline $\begin{array}{l}\text { Future Visions: the Unpublished } \\
\text { Papers of Abraham Maslow (1996) }\end{array}$ & - \\
\hline Total de Traduções & - \\
\hline
\end{tabular}

Ressaltamos que a obra Eupsychian Management, de 1965, foi relançada, nos EUA, com dois outros títulos: Maslow on Management, em 1998; e The Maslow Business Reader, em 2000. Foram publicações póstumas as obras The Farther Reaches of Human Nature, de 1971, e Future Visions: The Unpublished Papers of Abraham Maslow, de 1996. Observamos que dos 7 livros publicados por Maslow nos EUA, somente 2 foram traduzidos para o português brasileiro. A obra Introdução à Psicologia do Ser, traduzida em 1970, está com a edição esgotada. O livro Maslow no Gerenciamento, traduzido em 2000, teve a sua edição esgotada; posteriormente, em 2003, a obra foi relançada como Diário de Negócios de Maslow, ainda com edição disponível, e apresenta uma organização de Deborah Stephens sobre os diversos ensaios e as cartas de Maslow que interessam ao campo da Administração.

Além dessa análise, buscamos compilar outros livros que continham fontes textuais completas em capítulos

\footnotetext{
Nesta investigação, o site oficial de Maslow (2015) foi fundamental, por apresentar o registro de todas as suas publicações.
} 
de Maslow, e não fragmentos-trechos, traduzidos para o português brasileiro. Foram compiladas, pois, duas obras: Psicologia Humanista: entrevistas com Maslow, Murphy e Rogers, lançada em 1971, traduzida em 1975, e atualmente com edição esgotada. Trata-se de um capítulo que contém uma entrevista transcrita, concedida por Maslow a Willard Frick; e Psicologia Existencial - o que há nela para nós?, capítulo disponível no livro organizado por Rollo May, Psicologia Existencial, lançado em 1960 e traduzido em 1975, com edição atualmente esgotada.

Com efeito, em termos de recepção das obras maslownianas no Brasil, constatamos a existência de um livro (Maslow, 1962/1970), dois capítulos (Maslow, 1971/1975, 1960/1980) e dois livros (Maslow, 1965/2000, 1965/2003) que congregam diversos opúsculos de Maslow fielmente organizados por terceiros que o contataram. Ressaltamos que apenas um livro se encontra atualmente em circulação no mercado editorial brasileiro (Maslow, 1965/2003), com um título não sugestivo à Psicologia, Diário de negócios de Maslow; os outros quatro escritos não são mais publicados (Maslow, 1962/1970, 1971/1975, 1960/1980,
1965/2000). Constatamos, portanto, que, no que concerne a recepção das obras de Maslow no Brasil, há pouca circulação do seu pensamento na Psicologia.

Após essa análise, buscamos compilar autores brasileiros que produziram livros, específicos, sobre Maslow. Somente encontramos um livro, publicado em 2000, intitulado Saúde psicológica sob a perspectiva de Abraham Maslow, de Tânia Stoltz (2000). A despeito das limitações desse tipo de busca, num período de seis meses de procura em diversos sebos e livrarias físicas e virtuais, constatamos uma escassez de produções brasileiras de livros sobre Maslow.

Como resultado das duas investigações mencionadas, considerando os livros de Maslow traduzidos para o português brasileiro, o livro produzido sobre ele e os artigos publicados em periódicos de Psicologia, na Tabela 2, organizamos a distribuição ordenada, segundo o ano de lançamento no Brasil, das 14 publicações de e sobre Maslow no campo da Psicologia, ao longo dos anos. Os textos tabelados estão referenciados no final deste artigo.

Tabela 2: Distribuição temporal de publicações de e sobre Maslow na psicologia brasileira

\begin{tabular}{|c|c|}
\hline Título da Publicação & $\begin{array}{l}\text { Referência (Ano de Publicação Original } \\
\text { / Ano de Tradução) }\end{array}$ \\
\hline 1. Introdução à Psicologia do Ser & Maslow (1962/1970) \\
\hline 2. Entrevista com o Dr. Abraham Maslow & Maslow (1971/1975) \\
\hline 3. Psicologia Existencial - 0 que há nela para nós? & Maslow (1960/1980) \\
\hline 4. Motivação no trabalho: abordagens teóricas & Pérez-Ramos (1990) \\
\hline 5. Saúde psicológica sob a perspectiva de Abraham Maslow & Stoltz (2000) \\
\hline 6. Maslow no gerenciamento & Maslow (1965/2000) \\
\hline 7. Diário de negócios de Maslow & Maslow $(1965 / 2003)$ \\
\hline 8. A natureza motivacional dos valores humanos: evidências acerca de uma nova tipologia & Gouveia (2003) \\
\hline 9. Necessidades de saúde psicológica em crianças com deficiência mental & Araújo e Vieira (2005) \\
\hline 10. Conductas en el interior del transporte colectivo, conductores y semáforos & García-Cortés, Mendoza e Carmona (2007) \\
\hline 11. Mathematical formalization of theories of motivation proposed by Maslow and Herzberg & Kotliarov (2008) \\
\hline 12. Técnica de governo e práticas psicológicas: humanismo e empreendedorismo. & Ferreira, Curvello \& Monteiro (2009) \\
\hline 13. Experiencias cumbre en la consejería para las adicciones & Hoffman \& Ortiz (2010) \\
\hline 14. Reflexões críticas acerca da psicologia existencial de Rollo May & Ponte \& Sousa (2011) \\
\hline
\end{tabular}

Percebemos que não há uma constância de publicações de e sobre Maslow no campo da Psicologia, sobretudo a Humanista. A década de 2000, foi o período mais profícuo em termos de publicações que versaram a Psicologia de Maslow, com 71,4\% da produção. Considerando os resultados das investigações ora apresentadas, os dados demonstram que as ideias de Maslow são recebidas e circulam de uma forma restrita ao campo da Psicologia no Brasil. Curiosamente, o primeiro indício bibliográfico da recepção de Maslow no Brasil ocorreu no ano de sua morte, em 1970.

A terceira e última investigação empreendida sobre a recepção e circulação das ideias de Maslow no Brasil ocorreu mediante uma análise de livros na biblioteca de uma universidade pública federal. Pesquisas em bibliotecas demonstram uma perspectiva proveitosa de estudos em História da Psicologia (Campos \& Massimi, 1998) e ao modo de investigar como uma Psicologia migrou de um lugar para outro (Brožek, 1998). Consideramos que a biblioteca universitária é um espaço de circulação de diversos conhecimentos sobre uma Psicologia que apresentam alguns indícios representativos da recepção dela em um lugar. Os materiais disponíveis e dispersos na biblioteca utilizada constituíram, pois, fonte suplementar desta pesquisa.

Assinalamos que não encontramos nenhum livro de Maslow na biblioteca, contudo uma análise mais minuciosa 
constatou diversos livros gerais de Psicologia e de Administração que continham informações sobre ele. A despeito disso, o nosso foco foi analisar os tipos de ideias maslownianas que estavam disponíveis em tais livros. Assim, adotamos a seguinte lógica de investigação, conforme as etapas da pesquisa bibliográfica indicadas por Lima e Mioto (2007). Inicialmente, foi feita uma leitura de reconhecimento, ou seja, uma leitura rápida que visou eleger o material bibliográfico na biblioteca que potencialmente poderia ser pesquisado. Em seguida, realizou-se uma leitura exploratória sobre o material eleito para verificar se as informações ali contidas se relacionavam com o foco dessa investigação. Nesses dois primeiros momentos, foi estabelecido, como critério, que a amostra bibliográfica que seria coletada e analisada deveria conter, pelo menos, um capítulo, tópico ou subtópico que apresentasse alguma informação sobre Maslow e sua contribuição para a Psicologia e Administração.

Confirmado a pertinência no material, que perfez um total de 29 livros, realizou-se uma leitura seletiva mais minuciosa e criteriosa sobre o texto, de modo a identificar quais informações eram pertinentes à investigação. Foram rejeitados livros que apresentaram curtas menções a Maslow e que não especificaram ou destacaram suas ideias, especificamente, em um capítulo, tópico ou subtópico. Nessa etapa sobressaíram as informações sobre o tipo de livro e as ideias de Maslow contidas no texto analisado. Com base nesse material, disposto na Tabela 3, foram organizadas as seguintes informações sobre os livros que possuíam textos a respeito de Maslow.

Tabela 3: Livros que apresentam informações sobre Maslow

\begin{tabular}{lcc}
\multicolumn{1}{c}{ Tipo de livro } & Frequência & $\%$ \\
\hline Teorias da Personalidade & 2 & 6,8 \\
\hline Processos Psicológicos Básicos & 2 & 6,8 \\
\hline História da Psicologia & 3 & 10,3 \\
\hline Dicionário de Psicologia & 1 & 3,4 \\
\hline Introdução à Psicologia & 5 & 17,2 \\
\hline Psicologia Organizacional & 1 & 3,4 \\
\hline Administração & 15 & 51,7 \\
\hline Total & 29 & 100
\end{tabular}

Notamos que os livros de Administração $(51,7 \%)$ foram os que publicaram mais dados informacionais sobre as ideias de Maslow em seus capítulos, tópicos e subtópicos. Em seguida, na Tabela 4, distribuímos os conteúdos das ideias de Maslow disponíveis em todos os textos analisados.
Tabela 4: Ideias de Maslow disponíveis nos livros analisados

\begin{tabular}{lcc|}
\multicolumn{1}{c}{ Ideias de Maslow } & Frequência & $\%$ \\
\hline Natureza Humana & 1 & 2,0 \\
\hline Síndromes & 1 & 2,0 \\
\hline Autorrealização & 4 & 8,2 \\
\hline Motivação & 6 & 12,3 \\
\hline Fundação da Psicologia Humanista & 5 & 10,3 \\
\hline Biografia & 3 & 6,3 \\
\hline Antecedentes Intelectuais & 1 & 2,0 \\
\hline Experiência Culminante & 1 & 2,0 \\
\hline Valores & 1 & 2,0 \\
\hline Eupsiquia & 1 & 2,0 \\
\hline Psicologia Transpessoal & 1 & 2,0 \\
\hline Crescimento & 1 & 2,0 \\
\hline Self & 1 & 2,0 \\
\hline Personalidade & 1 & 2,0 \\
\hline Hierarquia das Necessidades Básicas & 21 & 42,9 \\
\hline Total & 49 & 100 \\
\hline
\end{tabular}

Percebemos que as ideias de Maslow mais trabalhadas nos livros analisados se referem à sua teoria da hierarquia das necessidades básicas (42,9\%), que contém a conhecida Pirâmide de Maslow, seguidas da teoria da motivação humana (12,3\%) e da relação de Maslow com a fundação da Psicologia Humanista (10,3\%). Esses dados coadunam com o que foi observado nos conteúdos dos artigos levantados na primeira investigação bibliográfica.

Embora a restrição da pesquisa a uma biblioteca evoque o questionamento sobre a sua representatividade dado que a mesma pesquisa em outras bibliotecas geraria outros resultados -, as informações aqui tabeladas e articuladas com os resultados obtidos pelas duas investigações anteriores possibilitam algumas discussões e inferências ponderadas a seguir: Primeira. A Psicologia Humanista de Maslow foi recebida no Brasil de um modo parcial e é incipiente a totalidade de sua obra, dado a carência de traduções dos seus livros para o português brasileiro, a falta de novas edições de suas obras já traduzidas e a pouca produção e circulação de artigos e livros específicos sobre ele no campo da Psicologia, sobretudo a Humanista.

Segunda. Maslow é mais popular em um circuito voltado para discussões relacionadas aos campos da Administração e da Psicologia Organizacional. Existe, também, um reconhecimento dele como um dos fundadores da Psicologia Humanista e como um teórico da motivação e das necessidades básicas. Em relação a estas teorias, ambas são vistas como ferramentas amplamente buscadas, ou mencionadas, por gestores para aumentar e direcionar a produtividade/satisfação de funcionários no trabalho, o que torna Maslow uma referência básica nesse tipo de discussão. A despeito disso, por um lado, Spector (1996/2012) aponta que as pesquisas empíricas sobre a teoria da hierarquia das necessidades básicas são inconclusivas ante a dificuldade de Maslow em definir o que é motivação e do argumento de que nem todas as 
necessidades básicas são motivadoras para certos tipos de pessoas. Por outro angulo, Sampaio $(2009)^{5}$, em uma revisão crítica dos trabalhos de Maslow sobre motivação, argumenta que os cenários da Psicologia Organizacional e da Administração reduziram e descaracterizaram o pensamento do humanista, pois perderam o horizonte de que os seus estudos “(...) tinham em vista o desenvolvimento de uma teoria que pudesse servir de base para a compreensão do homem inserido na sociedade, e não se aplica facilmente quando reduzida ao aspecto da vida laboral” (p, 06). Essa afirmação faz sentido, considerando a biografia de Maslow e de que, para Sampaio (2009), o expoente humanista sempre “(...) criticou a análise do homem quando se acha reduzida a apensa uma de suas dimensões, como o organismo, o inconsciente, o comportamento ou os papeis sociais" (p. 06), o mesmo ocorrendo com o mundo do trabalho.

Destarte, os estudos de Spector (1996/2012), Sampaio (2009) e as três investigações bibliográficas empreendidas, oferecem suporte para o entendimento sobre a recepção e circulação parcial das ideias de Maslow no Brasil, dado que: (1) nem todos os psicólogos humanistas se interessam pelos campos da Administração e da Psicologia Organizacional, ao passo que nem todos os psicólogos organizacionais e administradores se interessam pela Psicologia Humanista; (2) nos textos relacionados aos campos da Administração e da Psicologia Organizacional, por questões didáticas ao cumprimento da apresentação de um conteúdo básico, o pensamento de Maslow é reduzido teoricamente à dimensão do trabalho; (3) existem acusações de que a teoria de Maslow não possui sustentação empírica, conquanto sua classificação dos tipos de motivos seja derivada de suas observações inspiradas na Psicologia Clínica e Psicanálise norte-americana; (4) existe uma falta de exposição integral de todos os trabalhos de Maslow sobre motivação, que não concebia sua teoria como suficiente para o sucesso das organizações, dado que a autorrealização não está restrita apenas ao trabalho; (5) em muitos textos, não se incluem os desenvolvimentos de Maslow sobre as necessidades de sabedoria/entendimento e as necessidades estéticas, saúde psicológica, os valores do Ser (S), as metanecessidades, ciência psicológica, sociedade e educação. Os dois últimos itens, provavelmente, ocorrem em função da falta de traduções e reedições das obras de Maslow.

Terceira. Ainda assim, a ideia de Maslow que mais circula nos ambientes universitários é a da hierarquia das necessidades básicas. Quando se menciona algo sobre ele é comum se lembrar de sua pirâmide e vice-versa.

\footnotetext{
5 Elucidamos que, por uma questão de coerência e delimitação do método de revisão narrativa, o artigo de Sampaio (2009) não entrou nos dados levantados e tabulados pela primeira investigação bibliográfica, em razão do periódico que o publicou somente ter lançado, no SciELO, textos produzidos de 2011 até então. Não obstante, tomamos ciência do artigo e o indicamos como leitura para aprofundar a teoria da motivação de Maslow.
}

Esse esquema gráfico, possivelmente, popularizou e propagou a Psicologia Humanista de Maslow no Brasil, tornando-se ponto básico de menção em muitas disciplinas de Psicologia Organizacional, Gestão de Pessoas e Administração. Embora seja uma apresentação reduzida do pensamento maslowniano, essa figura gera um acesso ao seu conhecimento.

Quarta e última. Maslow não visitou o Brasil, ao contrário de outros psicólogos humanistas como Carl Rogers, Amedeo Giorgi, Rollo May, John Wood e Maureen O’Hara, nem encontramos registro de algum brasileiro que tenha ido estudar com Maslow, nos EUA, e tenha retornado para divulgar as suas ideias. Não houve, ainda, nenhum notório seguidor de Maslow que, de modo expressivo, tenha dado continuidade ao seu trabalho, desenvolvendo-o e promovendo-o, sobretudo no Brasil. Acrescentamos, ainda, que no cenário nacional não existe nenhum evento específico sobre Maslow. Indicamos, portanto, que todos esses fatores inferidos enfraqueceram a recepção e a circulação das ideias de Maslow na Psicologia Humanista brasileira.

\section{Considerações finais}

Esta pesquisa refletiu o percurso biográfico de Abraham Maslow e sua relação com a Psicologia Humanista nos EUA, para em seguida analisar os movimentos de recepção e circulação de suas ideias no Brasil, com base em três investigações bibliográficas. Constatamos que a vida e a obra de Maslow se misturam e possibilitam sua articulação com a Psicologia Humanista, para a qual ele tinha propósitos definidos antes, durante e depois da sua emergência. Verificamos que a Psicologia Humanista de Maslow chega parcialmente ao Brasil e a circulação de suas ideias, sobretudo a hierarquia das necessidades básicas, ocorre hegemonicamente no campo da Administração e da Psicologia Organizacional, circuito em que o expoente humanista é bastante mencionado, porém pouco aprofundado.

Em relação à pergunta lançada na introdução, agora com subsídios para respondê-la, ponderamos que o fator que, possivelmente, gera uma falta de conhecimento ou esquecimento de Maslow no movimento humanista brasileiro pode estar relacionado aos aspectos históricos de recepção e circulação de suas ideias em diversos meios bibliográficos de propagação de informações acadêmicas. Em uma medida contra o esquecimento, consideramos que as noções de recepção e circulação (Castelo-Branco et al., 2016), longe de serem exercidas como mecanismos avaliativos de uma abordagem humanista em detrimento de outra, implicam uma História contextual que entende os aspectos presentes em tal propagação e apropriação, sejam eles esquecidos ou pouco conhecidos.

Ainda há muito para se conhecer sobre Maslow, havendo a necessidade de mais pesquisas que aprofundem ou desenvolvam os seus aportes. Apontamos outras 
possibilidades de estudos que contrabalancem essa carência. Por exemplo, os arquivos de Maslow se encontram disponíveis no Museu de História da Psicologia, na Universidade de Akron, Ohio. Pesquisas historiográficas que trabalham com arquivos seriam uma possibilidade de acesso às nuances de Maslow. A elaboração de mais pesquisas teóricas e críticas sobre os principais conceitos maslownianos possibilitariam a movimentação de discussões sobre ele. Conquanto a teoria da hierarquia das necessidades básicas seja algo difundido, investigações empíricas que usem esse referencial, a partir da Psicologia Humanista e suas concepções de pesquisa, ofereceriam outra forma de desenvolver o legado de Maslow.

Concluímos que a Psicologia Humanista de Maslow ainda é um campo aberto de estudos no Brasil. Caso este artigo contribua com a divulgação de quem foi Maslow e alguns aspectos de sua Psicologia, para o público humanista e outros interessados, teremos alcançado o nosso propósito maior.

\section{Referências}

Amatuzzi, M. (2001). Por uma psicologia humana. Campinas, SP: Alínea.

Araújo, M. \& Vieira, J. (2005). Necessidades de saúde psicológica em crianças com deficiência mental. Psicologia: ciência e profissão, 25(4), 572-589.

Boainain, E. (1998). Tornar-se transpessoal: transcendência e espiritualidade na obra de Carl Rogers. São Paulo: Summus.

Brock, A. (2014). What is polycentric history of psychology? Estudos e Pesquisas em Psicologia, 14(2), 646-659.

Brožek, J. (1998). Abordagem quantitativa: Wundt na América. Em J. Brožek \& M. Massimi (Orgs.), Historiografia da psicologia moderna (p. 351-361). São Paulo: Unimarco; Loyola.

Buys, R. (2011). A Psicologia Humanista. Em A. Jacó-Vilela, A. Ferreira \& F. Portugal (Orgs.), História da psicologia: rumos e percursos (2. ed. p. 339-348). Rio de Janeiro: Nau.

Campos, R. \& Massimi, M. (1998). Arquivos e bibliotecas para a história da psicologia brasileira. Em J. Brožek \& M. Massimi (Orgs.), Historiografia da psicologia moderna (p. 305-313). São Paulo: Unimarco; Loyola.

Castanõn, G. (2007). Psicologia Humanista: a história de um dilema epistemológico. Memorandum, 12, 105-124.

Castelo-Branco, P., Rota, C., Miranda, R. \& Cirino, S. (2016). Recepção e circulação: implicações para pesquisas em história da psicologia. Em R. Assis \& S. Peres (Orgs.), História da Psicologia: tendências contemporâneas (p. 31-49). Belo Horizonte: Artesã.

Costa, A. \& Zoltowski, A. (2014). Como escrever um artigo de revisão sistemática. In S. Koller, M. Couto \& J. Hohendorff (Orgs.), Manual de produção científica (p. 55-70). Porto Alegre: Penso.
Cruz, R. (2016). A biografia na historiografia da psicologia: questões teóricas e metodológicas preliminares. Em R. Assis \& S. Peres (Orgs.), História da Psicologia: tendências contemporâneas (p. 51-69). Belo Horizonte: Artesã.

Dagfal, A. (2004). Para una «estética de la recepción» de las ideas psicológicas. Frenia, IV(2), 07-16.

Feijoo, A. \& Mattar, C. (2009). Psicologia Humanista e Psicologia Existencial. Em C. Tourinho \& R. Sampaio (Orgs.), Estudos em psicologia: uma introdução (p. 139-160). Niterói, RJ: Proclama.

Ferreira, A., Curvello, F. \& Monteiro, G. (2009). Técnica de governo e práticas psicológicas: humanismo e empreendedorismo. Temas em Psicologia, 17(1), 261-274.

García-Cortés, H., Mendoza, J. \& Carmona, M. (2007). Conductas en el interior del transporte colectivo, conductores y semáforos. Psicologia para América Latina, 10, 01-10.

Gendlin, E. (1992). Celebrações e Problemas da Psicologia Humanista. The Humanistic Psychologist (J. Messias, Trad.), 20(2), 447-460.

Gomes, W. (2010). Relações metodológicas entre fenomenologia, historiografia e psicologia humanista. Revista da Abordagem Gestáltica, 16(1), 03-11.

Gomes, W., Holanda, A. \& Gauer, G. (2004a). Primórdios da psicologia humanista no Brasil. Em Massimi, M. (Org.), História da psicologia no Brasil do Século XX (p. 87-104). São Paulo: E.P.U.

Gomes, W., Holanda, A. \& Gauer, G. (2004b). História das abordagens humanistas em psicologia no Brasil. Em Massimi, M. (Org.), História da psicologia no Brasil do Século XX (p. 105-129). São Paulo: E.P.U.

Gouveia, V. (2003). A natureza motivacional dos valores humanos: evidências acerca de uma nova tipologia. Estudos de Psicologia (Natal), 8(3), 431-443.

Grogan, J. (2013). Encountering America: Humanistic Psychology, sixties culture, and the shaping of the modern self. New York: Harper Collins Publisher.

Grynzspan, M. (2012). Por uma sociologia histórica da recepção e da circulação de textos. Revista de Sociologia e Política, 20(44), 11-30.

Hall, C., Lindzey, G. \& Campbell, J. (2000). Teorias da personalidade. Porto Alegre: Artmed. (Originalmente publicado em 1957).

Hall, M. (1968). A conversation with Abraham Maslow. Psychology Today, 2, 35-57.

Hoffman, E. (2008). Abraham Maslow: a biographer's reflections. Journal of Humanistic Psychology, 48(4), 439-443.

Hoffman, E. \& Ortiz, F. (2010). Experiencias cumbre en la consejería para las adicciones. Alternativas en Psicología, 15(23), 76-81.

Holanda, A. (2014). Fenomenologia e humanismo: reflexões necessárias. Curitiba: Juruá. 
Justo, H. (1978). Carl Rogers: teoria da personalidade, aprendizagem centrada no aluno (4. ed.). Porto Alegre: Livraria S. Antônio.

Kotliarov, I. (2008). Mathematical formalization of theories of motivation proposed by Maslow and Herzberg. Fractal: Revista de Psicologia, 20(2), 341-346.

Krüger, H. (2014). Psicologia Humanista. Em S. Araújo, F. Caropeso, G. Castanõn \& R. Simanke (Orgs.), Fundamentos filosóficos da psicologia contemporânea (p. 165-198). Juiz de Fora, MG: EDUFJF.

Lima, T. \& Mioto, R. (2007). Procedimentos metodológicos na construção do conhecimento científico: a pesquisa bibliográfica. Revista Katálysis, 10(esp), 37-45.

Maslow, A. (1966). The psychology of science: a reconnaissance. Chicago: Gateway.

Maslow, A. (1970). Introdução à Psicologia do Ser (A. Cabral, Trad.). Rio de Janeiro: Eldorado. (Originalmente publicado em 1962).

Maslow, A. (1971). The farther reaches of human nature. New York: Viking Press.

Maslow, A. (1975). Entrevista com o Dr. Abraham Maslow. Em W. Frick (Org.), Psicologia Humanista: entrevistas com Maslow, Murphy e Rogers (p. 33-68., E. Almeida, Trad.). Rio de Janeiro: Zahar. (Originalmente publicado em 1971).

Maslow, A. (1980). Psicologia Existencial - o que há nela para nós?. Em R. May (Org.), Psicologia Existencial (p. 57-66). Porto Alegre: Globo. (Originalmente publicado em 1960).

Maslow, A. (2000). Maslow no gerenciamento (E. Casquilho, Trad.). Rio de Janeiro: Qualitymark. (Originalmente publicado em 1965).

Maslow, A. (2003). Diário de negócios de Maslow (D. Sthephens, Org., N. Freire, Trad.). Rio de Janeiro: Qualitymark. (Originalmente publicado em 1965).

Maslow, A. (2015). Abraham Maslow publications: a current list of books and articles. Acesso em: 01 de junho, 2015. Disponível em: http://www.maslow.com/\#due>.

Moss, D. (2001). The roots and genealogy of humanistic psychology. Em K. Schneider. J. Bugental \& J. Pierson. (Eds.), The handbook of humanistic psychology: leading edges in theory, research and practice (p. 05-20). Thousands Oak, California: Sage.

Muto, S. \& Martin, F. (2009). Portrait of Adrian van Kaam and Humanistic Psychology. Journal of Humanistic Psychology, 49(3), 355-375.

Pérez-Ramos, J. (1990). Motivação no trabalho: abordagens teóricas. Psicologia USP, 1(2), 127-140.

Pickren, W. \& Rutherford, A. (2012). Rumo a uma história global da psicologia. Em S. Araújo (Org.), História e filosofia da psicologia: perspectivas contemporâneas (p. 57-66, G. Castañon \& S. Araújo, Trads.). Juiz de Fora, MG: UFJF.
Ponte, C. \& Sousa, H. (2011). Reflexões críticas acerca da psicologia existencial de Rollo May. Revista da Abordagem Gestáltica, 17(1), 47-58.

Rother, E. (2007). Revisão sistemática X revisão narrativa. Acta Paulista de Enfermagem, 20(2), v-vi.

Sampaio, J. (2009). O Maslow desconhecido: uma revisão de seus principais trabalhos sobre motivação. Revista de Administração (USP), 44(1), 5-16.

Society for Humanistic Psychology. (2016). Division 32. Acesso em 20 de abril, 2016. Disponível em: http://www.apadivisions.org/division-32/about/index.aspx>.

Spector, P. (2012). Psicologia nas organizações. São Paulo: Saraiva. (Originalmente publicado em 1996).

Stephens, D. (2003). Prefácio. Em A. Maslow. Diário de negócios de Maslow (D. Sthephens, Org., N. Freire, Trad.). Rio de Janeiro: Qualitymark. (Originalmente publicado em 1965).

Stoltz, T. (2000). Saúde psicológica sob a perspectiva de Abraham Maslow. Campinas, SP: Alínea.

Paulo Coelho Castelo Branco - Professor Adjunto I do Curso de Psicologia do Instituto Multidisciplinar em Saúde da Universidade Federal da Bahia (UFBA), Campus Anísio Teixeira - Vitória da Conquista. Doutor em Psicologia Social pela Universidade Federal de Minas Gerais (UFMG). Mestre em Psicologia pela Universidade Federal do Ceará (UFC), Graduado em Psicologia pela Universidade de Fortaleza (UNIFOR), com formação em Abordagem Centrada na Pessoa. Coordenador do Núcleo de Estudos em Psicologia Humanista (NEPH), com o apoio-financiamento do CNPq e da UFBA. Membro do GT de História da Psicologia da Associação Nacional de Pesquisa e Pós-graduação em Psicologia (ANPEPP); Sociedade Brasileira de História da Psicologia (SBHP); Sociedade Brasileira de Psicologia (SBP); Laboratório de Psicologia e Educação Helena Antipoff (LAPED); Grupo de Pesquisa Subjetividade e Práticas Clínico-Sociais; Grupo de Estudos e Pesquisas em História da Psicologia. Endereço Institucional: Universidade Federal da Bahia, Campus Anísio Teixeira, Instituto Multidisciplinar em Saúde, Gabinete 22, Rua Rio de Contas, 58, Bairro Candeias, CEP: 45029-094. Vitória da Conquista, Bahia. Telefone: (77) 3429-2730. E-mail:pauloccbranco@gmail.com

Luísa Xavier de Brito Silva - Graduada em Psicologia pela Universidade Federal da Bahia, no Instituto Multidisciplinar em Saúde no campus Anísio Teixeira, Vitória da Conquista, Bahia.

Recebido em 20.04.2016

Primeira Decisão Editorial em 04.11.2016

Aceito em 20.01.2017 